\title{
Influence of uniaxial stresses on electronic and optical properties of $\beta-\mathrm{K}_{2} \mathrm{SO}_{4}$ crystal $^{*}$
}

\author{
B. ANDRIYEVSKY ${ }^{1 \dagger}$, M. JASKÓlski ${ }^{1}$, V.Y. STADNYK ${ }^{2}$, M.O. ROMANYUK ${ }^{2}$, Z.O. KASHUbA ${ }^{2}$, \\ M.M. ROMANYUK ${ }^{3}$ \\ ${ }^{1}$ Faculty of Electronics and Computer Sciences, Koszalin University of Technology, 2 Śniadeckich Str., \\ PL-75-453, Koszalin, Poland \\ ${ }^{2}$ The Ivan Franko National University of Lviv, 8 Kyrylo-and-Mefodii Str., UA-79005 Lviv, Ukraine \\ ${ }^{3}$ National University "Lviv Politechnic”, 12 Bandera Street, UA-79013 Lviv, Ukraine
}

In view of possible practical applications of transparent crystals for mechanical stress sensors, theoretical investigation of piezo(elasto)optic effect in crystals might be useful for searching for proper materials, possessing large coefficients of elasto-optic effect, and for determination of uniaxial stress directions of maximum piezo-optical sensitivity. The influence of the uniaxial stresses on the electronic band structure, density of states, and optical properties of potassium sulphate crystal $\beta-\mathrm{K}_{2} \mathrm{SO}_{4}$ have been studied in the framework of the density functional theory using the $a b$ initio CASTEP code. Increase in the band gap, $E_{g}$ of the crystal takes place for three crystallographic directions and for moderate uniaxial stresses, $\sigma<1.5 \mathrm{GPa}$. Dependencies of principal refractive indices and polarizabilities upon principal uniaxial stresses are discussed together with other features of electronic structure of the crystal.

Keywords: crystals; insulators; electronic band structure; uniaxial stress; refractive indices

(C) Wroclaw University of Technology.

\section{Introduction}

Crystalline compounds of the general molecular formula $\mathrm{ABCX}_{4}$ are characterized by thermally stimulated structural phase transitions (PTs). It is also known that at the temperature range near a point of such PT, crystal structure and, e.g. optical properties may be very sensitive to the external influences, e.g. mechanical or thermal stresses [1]. This circumstance can be used for designing pressure or temperature sensors with relatively high characteristic coefficients. For instance, a crystal based elasto(piezo)-optic sensor can be designed for sensing and measuring mechanical pressure [2, 3]. One of the main problems related to this type of sensors is a proper crystal work at a given temperature to ensure high elasto-optic coefficients.

\footnotetext{
*This paper was presented at the $37^{\text {th }}$ International Microelectronics and Packaging IMAPS-CPMT Poland Conference, September 22 - 25, 2013, Kraków.

†E-mail: Bohdan.Andriyevskyy@tu.koszalin.pl
}

Experimental measurement of these coefficients is a complicated task and, therefore, the corresponding theoretical computational study of the band structure and related optical properties of a potential crystal could be helpful.

Potassium sulfate, $\mathrm{K}_{2} \mathrm{SO}_{4}$, is a crystal possessing both ionic and covalent type of bonds. The relatively strong covalent bonds exist between $\mathrm{SO}_{4}$ anions, whereas the weaker ionic interactions occur between potassium and sulphate ions. The crystal structure is unstable in a wide temperature range. $\mathrm{K}_{2} \mathrm{SO}_{4}$ is known to have different phases with different crystal symmetries in the solid state temperature range. The hexagonal, high temperature phase of the crystal is known as $\alpha-\mathrm{K}_{2} \mathrm{SO}_{4}(\mathrm{~T} \geqslant 860 \mathrm{~K})$ and the orthorhombic phase is defined as $\beta-\mathrm{K}_{2} \mathrm{SO}_{4}$ $(\mathrm{T} \leqslant 860 \mathrm{~K})$. In the hexagonal phase, the oxygen sites of the $\mathrm{SO}_{4}^{-}$anion are only partially occupied [4], which does not permit to perform corresponding $a b$ initio band structure calculations of the crystal using the adiabatic approximation of 
the density functional theory (DFT). A phase transition of the second order at the temperature of $56 \mathrm{~K}$ was detected in $\mathrm{K}_{2} \mathrm{SO}_{4}$ [5]. Below this temperature, the crystal is known as $\gamma-\mathrm{K}_{2} \mathrm{SO}_{4}$ with a monoclinic symmetry. The study of the electronic band structure and related properties of $\mathrm{K}_{2} \mathrm{SO}_{4}$ might be interesting because several crystals of the $\mathrm{K}_{2} \mathrm{SO}_{4}$ family (e.g. $\mathrm{Na}_{2} \mathrm{SO}_{4}, \mathrm{LiKSO}_{4}, \mathrm{~K}_{2} \mathrm{CrO}_{4}$, and $\mathrm{K}_{2} \mathrm{SeO}_{4}$ ) are characterized by the phase transformations from $\alpha$ - to $\beta$-phase $[6,7]$.

Optical properties of $\mathrm{K}_{2} \mathrm{SO}_{4}$ in the spectral range of transparency, $\mathrm{E}<5 \mathrm{eV}$, were studied at different temperatures [8-10]. One of the interesting results of these studies is that two isotropic points, related to refractive indices $\left(n_{i}=n_{j}, i, j=x\right.$, $\mathrm{y}$, or $\mathrm{z}$ ), were detected at the temperatures of $617 \mathrm{~K}$ and $700 \mathrm{~K}$, related to the orthorhombic phase of the crystal. Also, transition of the crystal into the hexagonal phase at temperatures $\mathrm{T}>860 \mathrm{~K}$ occurred through the intermediate phase (probably the incommensurate one) of very narrow range ( $4 \mathrm{~K}$ to $7 \mathrm{~K}$ ).

Taking into account the experimental results obtained for refractive indices and birefringence of $\mathrm{K}_{2} \mathrm{SO}_{4}$ [8-10], theoretical ab initio calculations of the corresponding optical properties might be interesting, as well.

First calculations of the band structure and optical properties of $\mathrm{K}_{2} \mathrm{SO}_{4}$ crystals were presented in the paper [11] using a norm-conserving pseudopotential method and a self-developed calculation program. Similar study on $\mathrm{K}_{2} \mathrm{SO}_{4}$ was performed by the authors using the CASTEP code [12].

In this work, optical spectra of refractive indices and birefringence were calculated in the photon energy range of fundamental electronic excitations and transparency of $\beta-\mathrm{K}_{2} \mathrm{SO}_{4}$ and piezooptical coefficients of the crystal have been obtained. However, electronic band structure and density of states of $\mathrm{K}_{2} \mathrm{SO}_{4}$, being the basic electronic properties of a crystal, have still not been calculated using modern DFT-based codes. Therefore, the electronic band structure, density of states, optical functions and influence of uniaxial stresses on these values of $\mathrm{K}_{2} \mathrm{SO}_{4}$ have been calculated and discussed in the present work using the CASTEP code (CAmbridge
Serial Total Energy Package). The study of the influence of large uniaxial stresses (up to $4 \mathrm{GPa}$ ) on the electronic and optical properties of $\mathrm{K}_{2} \mathrm{SO}_{4}$ crystals are of interest also because of the known difficulties in reaching such large uniaxial stresses in crystals experimentally (cracking of crystals).

\section{Method of calculations}

Calculations of the band structure and related properties of $\mathrm{K}_{2} \mathrm{SO}_{4}$ were performed using the CASTEP code (CAmbridge Serial Total Energy Package) [13] based on the density functional theory (DFT), ultrasoft pseudopotentials and planewave basis set. The generalized gradient approximation (GGA) for the exchange and correlation effects [14] with the ultrasoft pseudopotentials [15] was used in the calculations. The cutoff energy of $340 \mathrm{eV}$ was assumed in the plane-wave basis set. During self-consistent electronic minimization, the eigen-energy convergence tolerance was chosen to be $2.4 \times 10^{-7} \mathrm{eV}$ and the tolerance for the electronic total energy convergence in the optimization was $1 \times 10^{-5} \mathrm{eV}$. Moreover, the corresponding maximum ionic force tolerance was $3 \times 10^{-2} \mathrm{eV} / \AA$ and the maximum stress component tolerance was $5 \times 10^{-2} \mathrm{GPa}$. Optimization (relaxation) of the atomic positions and crystal unit cell parameters for every value of the uniaxial stress was performed before the calculations of the electronic characteristics: total electronic energy $\mathrm{E}$, band energy dispersion $\mathrm{E}(\mathrm{K})$, density of electronic states (DOS), and dielectric functions $\varepsilon(\mathrm{E})$. The band structure of the crystal was calculated for $18 \mathrm{~K}$-points of the Brillouin zone (BZ).

\section{Results and discussion}

For the $a b$ initio band structure calculations of $\mathrm{K}_{2} \mathrm{SO}_{4}$ the initial unit cell parameters, $\mathrm{a}=7.476 \AA$, $\mathrm{b}=5.763 \AA$, and $\mathrm{c}=10.071 \AA$, of $\beta-\mathrm{K}_{2} \mathrm{SO}_{4}$ crystal (orthorhombic space group $\mathrm{D}_{2 \mathrm{~h}}^{16}=$ Pnma) and corresponding positions of 28 constituent atoms (four formula units of $\beta-\mathrm{K}_{2} \mathrm{SO}_{4}$ in the unit cell) at the temperature $\mathrm{T}=298 \mathrm{~K}$ were taken from [16]. The relaxed (optimized) and the initial cartesian atomic coordinates of $\beta-\mathrm{K}_{2} \mathrm{SO}_{4}$ [16] were compared and 
the maximum deviation of atomic coordinates was found to be less than $0.13 \AA$. This indicates a good agreement between the calculated and experimental data.

For the studied crystal, eight groups of valence bands (VBs) in the range of -28 to $0 \mathrm{eV}$ have been obtained (Fig. 1). All VBs show a relatively small dispersion $\mathrm{E}(\mathrm{K})$ (dependence of the electron energy $\mathrm{E}$ versus wave vector $\mathrm{K}$ ). A very similar band structure has been observed for $\mathrm{RbNH}_{4} \mathrm{SO}_{4}$ crystals containing sulphate group $\mathrm{SO}_{4}$ [17]. Small differences in the positions of VBs observed for $\mathrm{K}_{2} \mathrm{SO}_{4}$ and $\mathrm{RbNH}_{4} \mathrm{SO}_{4}$ [17] could be also attributed to the different levels of theory (LDA or GGA) used in those studies. The energy band gap, $\mathrm{E}_{\mathrm{g}}$ of $\mathrm{K}_{2} \mathrm{SO}_{4}$, is found to be direct and is equal to $\mathrm{E}_{\mathrm{g}}=5.2 \mathrm{eV}$. This magnitude, however, is approximately $2 \mathrm{eV}$ smaller than the photon energy of the experimental long-wave absorption edge of the crystal [18]. Such discrepancy in the values of the theoretical and experimental band gaps $\left(\mathrm{E}_{\mathrm{g}}^{\text {(theor })}<\mathrm{E}_{\mathrm{g}}^{\text {(exper) }}\right.$ ) has also been observed for other crystals, when the DFT method has been used.

Two upper VBs of the crystal, especially the top one, originate mainly from the $\mathrm{p}$-states of oxygen (Fig. 1). The bottom CB is formed by the s-states of potassium. The higher laying $\mathrm{CBs}$ are more hybridized that is rather a common feature of the material. The fifth VB at the energy near $-11 \mathrm{eV}$ is formed mainly by the $\mathrm{p}$-states of potassium. A low degree of hybridization of this VB indicates a small covalent character of the potassium related interatomic bonds. The lower laying $\operatorname{VBs}(\mathrm{E}<-18 \mathrm{eV})$ are mainly of s-type, which is an expected tendency.

Absolute values of Mulliken charges for sulfur (2.08) and oxygen (0.98 to 1.01) (Table 1) and averaged distance $\mathrm{S}-\mathrm{O}$ (1.49 to 1.50$)$ were found to be a bit larger in comparison to the similar values in $\mathrm{RbNH}_{4} \mathrm{SO}_{4}$ [17]. This indicates higher ionicity of $\mathrm{S}-\mathrm{O}$ bonds in $\mathrm{K}_{2} \mathrm{SO}_{4}$ than in $\mathrm{RbNH}_{4} \mathrm{SO}_{4}$. Analysis of Mulliken atomic populations of $\mathrm{K}_{2} \mathrm{SO}_{4}$ revealed a considerable charge stability of the sulphate groups $\mathrm{SO}_{4}$ in respect to the uniaxial stresses along $\mathrm{x}$-axis up to $\sigma_{\mathrm{x}}=8 \mathrm{GPa}$ (Table 1). Such a stress leads, however, to decreasing of p-electrons

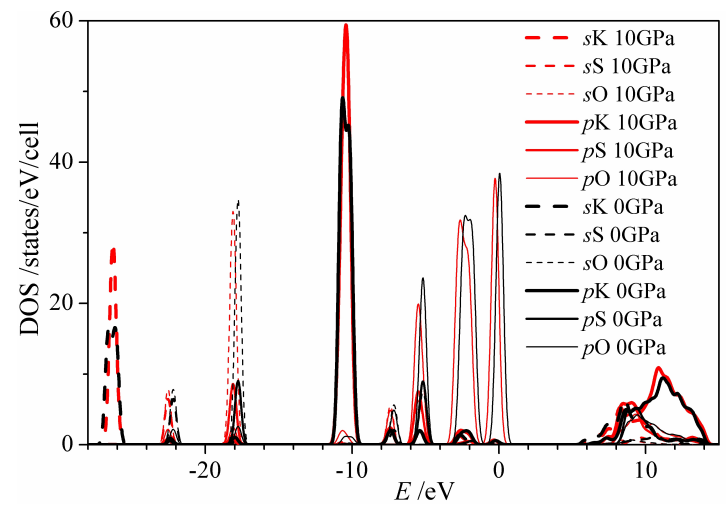

Fig. 1. Projected DOS on the s- and p-orbitals and on the atomic units of $\beta-\mathrm{K}_{2} \mathrm{SO}_{4}$ for uniaxial stresses $\sigma_{\mathrm{x}}=0$ and $10 \mathrm{GPa}$.

charge difference between $\mathrm{K} 1$ and $\mathrm{K} 2$ units (Table 1). Charge stability of the sulphate groups, $\mathrm{SO}_{4}$ in respect to the uniaxial stresses is probably an evidence of the strong covalent $\mathrm{S}-\mathrm{O}$ bonds. This stability is also an evidence of the relative isolation of $\mathrm{SO}_{4}$ groups in the crystal, which is in agreement with the small band dispersion $\mathrm{E}(\mathrm{K})$.

On the basis of the results on Mulliken population and interatomic distances of $\mathrm{K}_{2} \mathrm{SO}_{4}$, one can conclude that under external influences (uniaxial stress, for example) the geometry (linear dimensions) of the sulphate units $\mathrm{SO}_{4}$ is very stable. However, rotations of these units in the crystal unit cell of $\mathrm{K}_{2} \mathrm{SO}_{4}$ are more probable due to the weaker interatomic bonding between sulphate $\left(\mathrm{SO}_{4}\right)$ and potassium $(\mathrm{K})$ units. This conclusion is in agreement with experimental data for $\mathrm{K}_{2} \mathrm{SO}_{4}$ crystal structures at different temperatures and corresponding experimental models of structural phase transitions.

We have obtained also the band structure characteristics of $\beta-\mathrm{K}_{2} \mathrm{SO}_{4}$ for uniaxial stresses applied to the crystal along its crystallographic axes. One of the consequences of the uniaxial stress is energy shift of the bands, mainly the negative shift for the valence bands $\left(\Delta \mathrm{E}_{\mathrm{VB}}<0\right)$ and positive shift for conduction bands $\left(\Delta \mathrm{E}_{\mathrm{CB}}>0\right)$ (Fig. 1). Therefore, for different directions, and not very large stress values, the stress induced increase of the band gap, $E_{g}$ is expected. Similar effect takes place for hydrostatic pressure. 
Table 1. Mulliken atomic populations for s- and p-orbitals and atomic charges of $\mathrm{K}_{2} \mathrm{SO}_{4}$ atomic units at different uniaxial stresses, $\sigma_{\mathrm{x}}$ along $\mathrm{x}$-axis.

\begin{tabular}{llllllrlrrr}
\hline $\begin{array}{c}\text { Atomic } \\
\text { unit }\end{array}$ & \multicolumn{4}{c}{$\sigma_{\mathrm{x}}=0$} & \multicolumn{3}{c}{$\sigma_{\mathrm{x}}=2 \mathrm{GPa}$} & \multicolumn{2}{c}{$\sigma_{\mathrm{x}}=8 \mathrm{GPa}$} \\
\cline { 2 - 10 } & $\mathrm{s}$ & $\mathrm{p}$ & $\begin{array}{l}\text { charge } \\
{[\mathrm{e}]}\end{array}$ & $\mathrm{s}$ & $\mathrm{p}$ & \multicolumn{1}{c}{$\begin{array}{c}\text { charge } \\
{[\mathrm{e}]}\end{array}$} & $\mathrm{s}$ & $\mathrm{p}$ & \multicolumn{1}{c}{$\begin{array}{c}\text { charge } \\
\text { [e] }\end{array}$} \\
\hline \hline $\mathrm{K} 1$ & 2.14 & 5.86 & 0.91 & 2.15 & 5.87 & 0.97 & 2.14 & 5.90 & 0.97 \\
$\mathrm{~K} 2$ & 2.08 & 6.00 & 1.00 & 2.08 & 5.97 & 0.95 & 2.06 & 5.94 & 1.00 \\
$\mathrm{~S}$ & 1.24 & 2.69 & 2.08 & 1.24 & 2.69 & 2.21 & 1.23 & 2.67 & 2.09 \\
$\mathrm{O} 1$ & 1.89 & 5.09 & -0.98 & 1.90 & 5.09 & -0.96 & 1.91 & 5.10 & -1.01 \\
$\mathrm{O} 2$ & 1.90 & 5.11 & -1.01 & 1.90 & 5.11 & -0.96 & 1.90 & 5.11 & -1.02 \\
$\mathrm{O} 3$ & 1.90 & 5.10 & -1.00 & 1.90 & 5.10 & -0.96 & 1.90 & 5.12 & -1.02 \\
\hline
\end{tabular}

Changes in the VBs density of states near $-10 \mathrm{eV}$ and $-26 \mathrm{eV}$, corresponding mainly to the potassium states, are among the largest changes, appearing as an increase in PDOS upon an increase in the uniaxial stress $\sigma_{\mathrm{X}}$ (Fig. 1). More detailed consideration has revealed that at the relaxed state of the crystal $(\sigma=0)$ PDOS bands at $-10 \mathrm{eV}$ and $-26 \mathrm{eV}$ for two symmetry different sites of potassium atoms $\mathrm{K} 1$ and $\mathrm{K} 2$ are not identical, which leads to the clear energy shifts of the corresponding PDOS maxima. It was revealed also that in the case of stress $\sigma_{\mathrm{x}}$ the difference between positions of these PDOS maxima decreases when the uniaxial stress increases, which leads to the increase of PDOS for both K1 and K2 atoms (Fig. 1). Similar energy shifts of $\mathrm{K} 1$ and $\mathrm{K} 2$ bands for stresses along $\mathrm{y}$ - and z-directions are smaller than in the case of $\mathrm{x}$-direction and are of the opposite sign.

Behavior of the band gap, $\mathrm{E}_{\mathrm{g}}$ of the crystal upon decrease in the relative inverse volume $\mathrm{V}_{0} / \mathrm{V}$, corresponding to the relative density $\rho / \rho_{0}$ increase, is similar for relatively small compressions, $\mathrm{V}_{0} / \mathrm{V}<1.01$ (Fig. 2). For larger compressions, $\mathrm{V}_{0} / \mathrm{V}>1.01$, characters of these dependencies are different for different directions of the uniaxial stress (Fig. 2). Generally, we can associate the changes in behavior of the dependencies $\mathrm{E}_{\mathrm{g}}\left(\mathrm{V}_{0} / \mathrm{V}\right)_{\mathrm{y}}$ and $\mathrm{E}_{\mathrm{g}}\left(\mathrm{V}_{0} / \mathrm{V}\right)_{\mathrm{z}}$, mentioned above, with the changes in signs of the effective screening potential for those $\mathrm{VB}$ and $\mathrm{CB}$ electronic states near the band gap, $\mathrm{E}_{\mathrm{g}}$ of the crystal. These screening potential probably results from the influence of electronic states, which do not participate directly in the optical transition corresponding to the band gap $\mathrm{E}_{\mathrm{g}}$. We should admit here that hydrostatic pressure of the value corresponding to $\mathrm{V}_{0} / \mathrm{V}=1.10$ leads only to the increase in the band gap $E_{g}$. Coefficients of the uniaxial pressure dependencies of the band gap of $\mathrm{K}_{2} \mathrm{SO}_{4}$ are as follows: $\mathrm{dE} / \mathrm{d} \sigma_{\mathrm{x}}=0.080 \mathrm{eV} / \mathrm{GPa}, \mathrm{dE} / \mathrm{d} \sigma_{\mathrm{y}}=$ $0.058 \mathrm{eV} / \mathrm{GPa}, \mathrm{dE} / \mathrm{d} \sigma_{\mathrm{z}}=0.054 \mathrm{eV} / \mathrm{GPa}$.

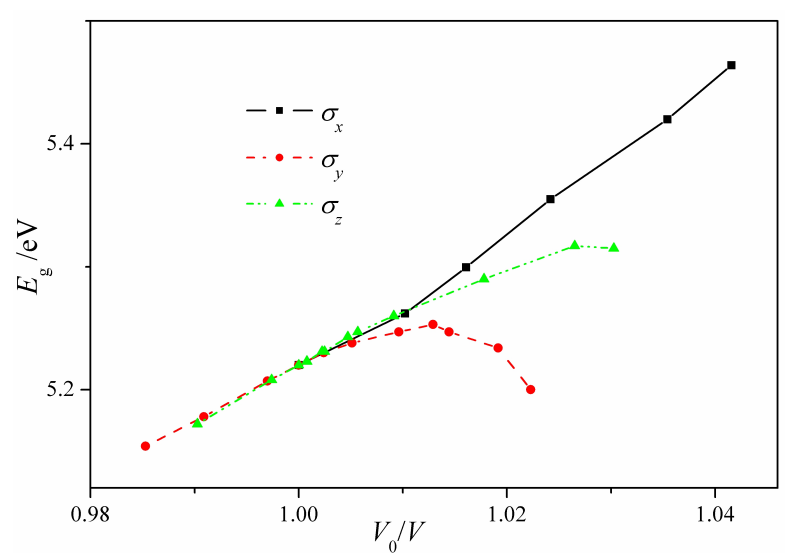

Fig. 2. Band gap of $\mathrm{K}_{2} \mathrm{SO}_{4}, \mathrm{E}_{\mathrm{g}}$ versus relative inverse unit cell volume $\mathrm{V}_{0} / \mathrm{V}$ for uniaxial stresses $\sigma_{\mathrm{x}}$, $\sigma_{\mathrm{y}}$, and $\sigma_{\mathrm{z}}$.

On the basis of the band structures of $\mathrm{K}_{2} \mathrm{SO}_{4}$ calculated for different uniaxial stresses $\sigma_{\mathrm{j}}$ we have obtained the corresponding dependencies of refractive indices $n_{i}\left(\sigma_{j}\right)(\mathrm{i}, \mathrm{j}=\mathrm{x}, \mathrm{y}, \mathrm{z})$. A monotonous increase of three refractive indices $n_{i}$ of $\mathrm{K}_{2} \mathrm{SO}_{4}$ upon three uniaxial stresses $\sigma_{\mathrm{j}}$ is observed. This takes place because of the expected inversely 
proportional dependence of the refractive index upon the unit cell volume of any material.

One of the features of the obtained dependencies of $n_{i}\left(\sigma_{j}\right)$ are the smallest averaged slopes for indices $\mathrm{i}=\mathrm{j}$. This feature is consistent with the smallest diagonal components of the piezo-optic tensor of the crystal, obtained earlier [12]. Also, for all three Cartesian directions of uniaxial stress $\sigma_{i}$ $(\mathrm{i}=\mathrm{x}, \mathrm{y}, \mathrm{z})$, the isotropic points of the refractive indices, $\mathrm{n}_{\mathrm{y}}=\mathrm{n}_{\mathrm{z}}$ and $\mathrm{n}_{\mathrm{x}}=\mathrm{n}_{\mathrm{z}}$, have been found in the range of $\sigma_{i}<5 \mathrm{GPa}$.

Since CASTEP calculates the imaginary part $\varepsilon_{2}$ of the dielectric constant using the equation [19]:

$$
\varepsilon_{2}(E)=\frac{2 e^{2} \pi}{V \varepsilon_{0}} \sum_{k, v, c}\left|\left\langle\Psi_{k}^{c}|\hat{u} \cdot \eta| \Psi_{k}^{v}\right\rangle\right|^{2} \delta\left(E_{k}^{c}-E_{k}^{v}-E\right)
$$

and the real part $\varepsilon_{1}$ of dielectric function is calculated using the Kramers-Kronig relation:

$$
\varepsilon_{1}(E)-1=\frac{2}{\pi} \int_{0}^{\infty} \frac{t \varepsilon_{2}(t) d t}{t^{2}-E^{2}}
$$

the product $\left(\varepsilon_{1}-1\right) \mathrm{V}=\left(\mathrm{n}^{2}-1\right) \mathrm{V}$ should be independent of the volume $\mathrm{V}$, at this first approximation. Therefore, the analysis of the dependencies $\left(\mathrm{n}^{2}-1\right) \mathrm{V}$ upon stress $\sigma$ or relative inverse volume $\mathrm{V}_{0} / \mathrm{V}$ should be more convenient to reveal corresponding features of the averaged optical matrix element (derived from the equation 1) than similar dependencies of the refractive index $n$ or susceptibility $\chi=\left(n^{2}-1\right)$. The value $\left(n^{2}-1\right) V$ is close to the refraction, $R=\left(n^{2}-1\right) M /\left(n^{2}+2\right) / \rho$, which, in turn, is proportional to the polarizability $\alpha, \mathrm{R}=4 \pi \mathrm{N} \alpha / 3$ [20]. Therefore, the functional dependencies of the value $\left(n^{2}-1\right) V$ obtained here may be close to the functional dependencies of polarizability $\alpha$.

The dependencies of $\left(n^{2}-1\right) V$ upon $V_{0} / V$ obtained for $\mathrm{K}_{2} \mathrm{SO}_{4}$ are presented in Fig. 3 to 5 . Behaviors of these dependencies, for the uniaxial stress along $\mathrm{x}$-axis (Fig. 3), are a bit different from those for $y$ - and z-directions (Fig. 4 and 5, respectively). Maximal relative decrease of the value $\left(\mathrm{n}^{2}-1\right) \mathrm{V}$ upon increase of the relative inverse volume $\left(\mathrm{V}_{0} / \mathrm{V}\right)_{\mathrm{x}}$ is equal to $0.5 \%$, whereas similar values for $\mathrm{y}$ - and $\mathrm{z}$-axes are twice larger $(2 \%)$. Thus, the sensitivity of electronic system of the crystal to the uniaxial stress along $\mathrm{x}$-axis is the smallest compared to the directions along $\mathrm{y}$ - and $\mathrm{z}$-axes. Also, in the cases of stresses in $y$ - and z-directions, the value $\left(n^{2}-1\right) \mathrm{V}$ for two of three light polarizations are almost independent of the value $\mathrm{V}_{0} / \mathrm{V}$ (Fig. 4 and 5). Moreover, in the case of $\sigma_{y}$, a slight increase in $\left(n^{2}-1\right) \mathrm{V}$ upon increase of $\mathrm{V}_{0} / \mathrm{V}$ is observed (Fig. 4, 5). The largest changes in the value $\left(\mathrm{n}^{2}-1\right) \mathrm{V}$ are observed in the directions coincided with directions of uniaxial stress (Fig. 3 to 5). It should be stressed here that these changes are negative for three axes, $x, y$, and $z$. One can interpret this qualitatively as a result of some pushing off the electronic p-orbitals outside the stress direction. As a result, this should lead to an increase of p-orbitals components onto the perpendicular cartesian directions. Such interpretation is in agreement with the results presented in Fig. 3 to 5.

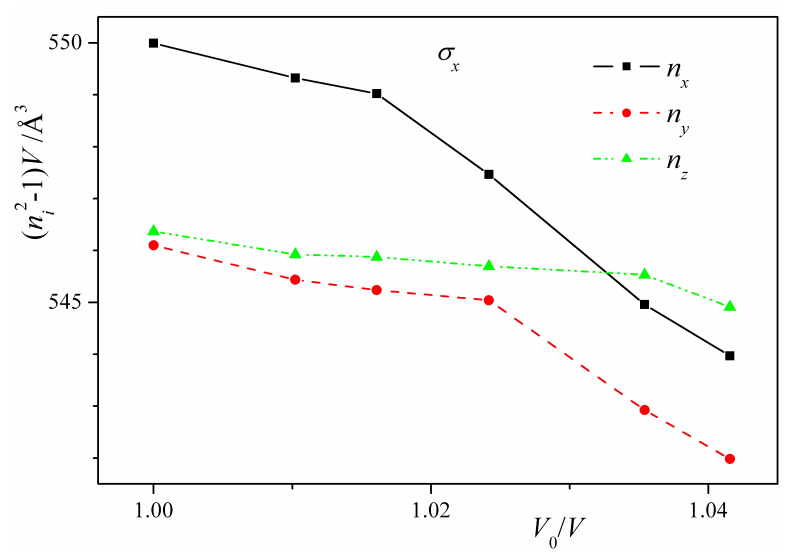

Fig. 3. Dependencies of $\left(n^{2}-1\right) V(n$ is at photon energy $\mathrm{E}=0.01 \mathrm{eV}$ ) caused by the uniaxial stress $\sigma_{\mathrm{x}}$ for $\mathrm{K}_{2} \mathrm{SO}_{4}$ versus relative inverse unit cell volume $\mathrm{V}_{0} / \mathrm{V}$.

\section{Conclusions}

Electronic band structure of $\mathrm{K}_{2} \mathrm{SO}_{4}$ crystals has been calculated in the framework of density functional theory using CASTEP code. Also the origin of the valence and conduction bands has been determined. Two upper VBs of the crystal, especially the top one, originate mainly from the p-states of oxygen. The bottom CB is formed by the s-states of potassium. 


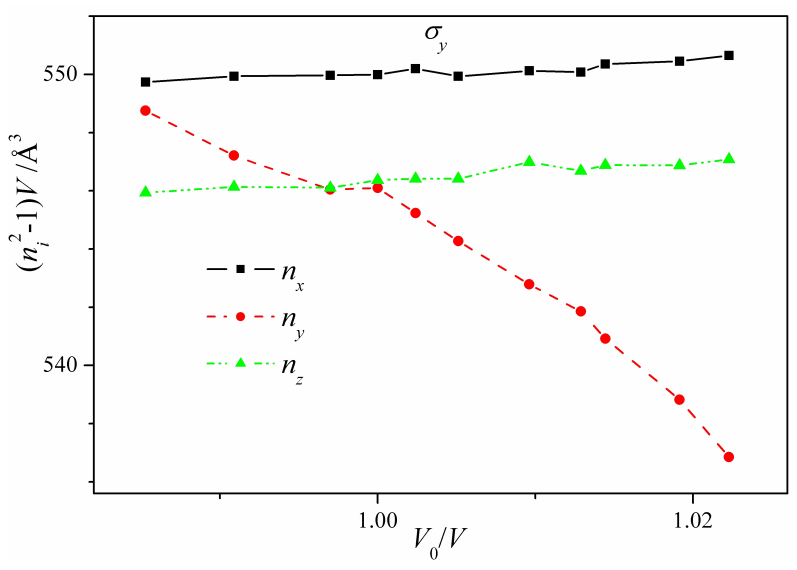

Fig. 4. Dependencies of $\left(n^{2}-1\right) V(n$ is at photon energy $\mathrm{E}=0.01 \mathrm{eV}$ ) caused by the uniaxial stress $\sigma_{\mathrm{y}}$ for $\mathrm{K}_{2} \mathrm{SO}_{4}$ versus relative inverse unit cell volume $\mathrm{V}_{0} / \mathrm{V}$.

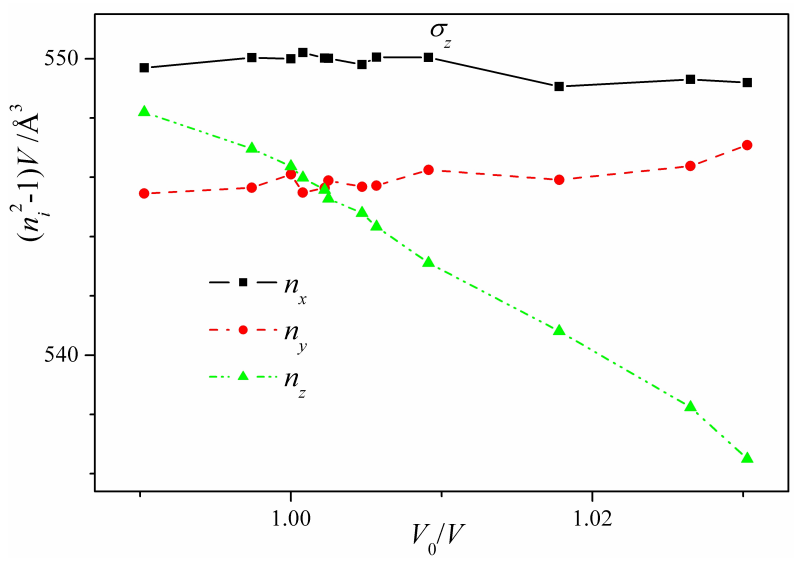

Fig. 5. Dependencies of $\left(n^{2}-1\right) V(n$ is at photon energy $\mathrm{E}=0.01 \mathrm{eV}$ ) caused by the uniaxial stress $\sigma_{\mathrm{z}}$ for $\mathrm{K}_{2} \mathrm{SO}_{4}$ versus relative inverse unit cell volume $\mathrm{V}_{0} / \mathrm{V}$.

Computationally simulated uniaxial stresses $\sigma<1.5 \mathrm{GPa}$ along crystallographic directions of $\mathrm{K}_{2} \mathrm{SO}_{4}$ crystals led to an increase in the band gap $\mathrm{E}_{\mathrm{g}}$ with the rates of $\mathrm{dE}_{\mathrm{g}} / \mathrm{d} \sigma_{\mathrm{x}}=$ $0.080 \mathrm{eV} / \mathrm{GPa}, \mathrm{dE} / \mathrm{d} \sigma_{\mathrm{y}}=0.058 \mathrm{eV} / \mathrm{GPa}$, and $\mathrm{dE}_{\mathrm{g}} / \mathrm{d} \sigma_{\mathrm{z}}=0.054 \mathrm{eV} / \mathrm{GPa}$. Similar effect (increase of $E_{g}$ ) was observed for the case of hydrostatic compression of the crystal.

Two isotropic points of the refractive indices, $\mathrm{n}_{\mathrm{y}}=\mathrm{n}_{\mathrm{z}}$ and $\mathrm{n}_{\mathrm{x}}=\mathrm{n}_{\mathrm{z}}$, induced by the computationally simulated uniaxial stresses $\sigma_{i}(i=x, y, z)$, were found for $\mathrm{K}_{2} \mathrm{SO}_{4}$ crystals in the range of uniaxial stresses $\sigma_{\mathrm{i}}<5 \mathrm{GPa}$.

The value $\left(n^{2}-1\right) \mathrm{V}$, proportional to the electronic polarizability $\alpha$ of the crystal, seems to be convenient for characterization of piezo- and elasto-optical effects, which occur upon a change in the unit cell volume $\mathrm{V}$. The largest decrease in the values $\left(\mathrm{n}_{i}^{2}-1\right) \mathrm{V}$ of $\mathrm{K}_{2} \mathrm{SO}_{4}$ have been observed for directions of light polarization $i(i=x, y, z)$ coincided with directions of the uniaxial stress $\sigma_{i}$.

\section{Acknowledgements}

The calculations were performed using the Accelrys Materials Studio 6.0 package in the supercomputer centre ICM of Warsaw University in the framework of the project G26-3.

\section{References}

[1] Narasimhamurty T.S., Photoelastic and electrooptic properties of crystals, Plenum Press, 1981.

[2] LI C., Appl. Optics, 50 (2011), 5315.

[3] Pitts T.A., Sagers A., Greenleaf J.F., IEEE T. Ultrason. Ferr., 48 (2001), 1686.

[4] Arnold H., Kurtz W., Richter-Zinnius A., Bethke J., Heger G., Acta Crystallogr. B, 37 (1981), 1643.

[5] Ahmed S.A., Phys. Status Solidi B, 195 (1996), 113.

[6] Aleksandrov K.S., Beznosikov B.V., Ferroelectrics, 117 (1991), 331.

[7] Russell S.D., Merlin R., Phys. Rev. B, 33 (1986), 1871.

[8] Zheludev I.S., GABA V.M., RomanyuK N.A., URSUL Z.M., Izv. AN USSR, 7 (2) (1986), 386 (in Russian).

[9] Romanyuk N.A., Gaba V.M., Ursul Z.M., StadNYK V.Yo., Opt. Spectrosc.+, 62 (1) (1987), 94 (in Russian).

[10] Stadnyk V.Yo., Romanyuk M.O., Chyzh O.Z., VAchulovych V.F., Condens. Matter Phys., 10 (49) (2007), 45.

[11] Kityk I.V., Andriyevsky B.V., Yuvshenko V.O., Phys. Status Solidi B, 182 (1994), K79.

[12] Andriyevsky B., Romanyuk M., Stadnyk V., J. Phys. Chem. Solids, 70 (2009), 1109.

[13] Clark S.J., Segall M.D., Pickard C.J., Hasnip P.J., Probert M.J., Refson K., Payne M.C., Z. Kristallogr, 220 (2005), 567.

[14] Perdew J.P., Chevary J.A., Vosko S.H., JaCkson K.A., Pederson M.R., Singh D.J., Fiolhais C., Phys. Rev. B, 46 (1992), 6671.

[15] Vanderbilt D., Phys. Rev. B, 41 (1990), 7892.

[16] McGinnety J.A., Acta Crystallogr. B, 28 (1972), 2845.

[17] Andriyevsky B., Ciepluch-Trojanek W., StadNyK V., TuZyak M., Romanyuk M., Kurlyak V., J. Phys. Chem. Solids, 68 (2007), 1892. 
[18] Andriyevsky B.V., Kurlyak V.Yu., RomanyuK N.A., URsul Z.M., Opt. Spectrosc. +, 66 (1989), 623.

[19] http://www.tcm.phy.cam.ac.uk/castep/ documentation/WebHelp/CASTEP.html.
[20] Born M., Wolf E., Principles of Optics, Pergamon, Oxford, 1984.

Received 2013-01-30 Accepted 2014-11-06 